\title{
Entre la violencia y el consentimiento: el rapto de mujeres tapatías en tiempos pasados
}

DOI: https://doi.org/10.32870/dse.v0i10.290

Benítez, Laura (2014). Por la palabra de matrimonio. El rapto en Guadalajara (1885-1933). Guadalajara: Univesidad de Guadalajara.

\section{Laura Catalina Díaz Robles*}

El texto que reseño en esta ocasión representa la cristalización de una tesis que una vez pulida para formato de libro, puede llegar a nuestras manos. Desde que Laura Benítez me platicó que en su investigación para titularse había abordado el rapto de mujeres en Guadalajara me vinieron a la cabeza todas aquellas jóvenes de mi familia y entorno cercano que pasaron por el mismo trance, al igual que aquellos casos en que la literatura y el cine trataron el tema y la forma en que lo habían hecho; y me pareció fascinante que ella historizara ese proceso que podría parecer trivial por cotidiano, pero que permite desde el espacio íntimo de las personas involucradas, ver cómo se concebía el espacio público.

Entonces yo tenía poco de conversa a la historia, estaba acostumbrada a leer historias como la que señala Laura en su introducción, sobre cuestiones políticas y económicas, que ponían especial atención a las clases dominantes diciendo a qué se dedicaban, cómo debían de comportarse, cuáles eran sus diversiones, cómo vivían, cuáles eran los prototipos ideales. Cito: “... mi interés es dar voz a los sin voz, a los hombres y mujeres que tenían que trabajar todo un día para poder subsistir, a las familias que eran víctimas del deshonor causado por el rapto de alguna de sus hijas y a todos aquellos que pretendieron dar inicio a su matrimonio a través de un delito como el rapto". (p. 17), que no obstante ser castigado por normas judiciales, eclesiásticas y sociales, era una práctica común.

Es una historia de hombres y mujeres que nos marca los prototipos de género de la época y cómo eran transgredidos, asimismo cómo quienes detentaban el paradigma de orden y progreso pretendían sostenerlos. Laura construye una historia de las mujeres raptadas en relación con los hombres raptores a partir de la elaboración discursiva que ellos realizan, y que muchas veces es contrastante con el discurso elaborado para normar sus cuerpos.

* Doctora en Ciencias Sociales por el Colegio de Michoacán. Profesora/investigadora en el Departamento de Estudios en Educación de la Universidad de Guadalajara. Correo electrónico: catidr@yahoo.com.mx 
En el momento en que Laura Benitez recurre al Archivo del Supremo Tribunal de Justicia del Estado de Jalisco para recabar sus fuentes primarias, éste no se encontraba completamente catalogado y en un repositorio único, sino que encuentra una parte en el propio Tribunal, otra en el Archivo Histórico de Jalisco y otra, la más antigua, en la Biblioteca Pública del Estado de Jalisco. Por la necesidad que había de revisar expediente por expediente del ramo de juzgados menores, requirió de una autorización del Consejo General del Poder Judicial, lo que es indicativo de un trabajo serio, y desde la perspectiva histórica estamos ante una primicia, o quizá en la actualidad un tema que empieza a ser del interés de otros investigadores. Los datos obtenidos en los archivos judiciales constituyen la columna de su investigación, pero también echa mano de misceláneas, hemerografía, legislación, novelas.

Para analizar la información que obtuvo, la autora construye una base de datos y encuentra variables como nombre, edad, estado civil, oficio, firma, declaración, que luego ella trabaja cronológicamente, por tipo de rapto, por oficios, por edades, por la finalidad del rapto, o por el tipo de declaraciones. Así nos damos cuenta de qué era lo que pedían las madres, qué era en el fondo lo que les preocupaba después de que sus hijas fueran raptadas voluntariamente o no, y después, abandonadas con las consecuencias subsiguientes para su honor, su prole si es que la había y su economía.

El libro inicia con un extenso e interesante tratamiento sobre la legislación del rapto, desde los romanos hasta los primeros códigos latinos y lo que al respecto señalaban los códigos del Estado de Jalisco (1885, 1923 y 1933). Este recorrido legal nos permite entender que el plagio de una joven no ha tenido el mismo significado en toda época y lugar, y que se ha llevado a cabo por diferentes motivos, lo que ha posibilitado considerarlo en ocasiones como una trasgresión fuerte, donde el trasgresor requería de un castigo ejemplar, o ha bajado de tono y carga dramática, por lo que se consideró un delito menor. Delito siempre, los castigados varían según la época y lugar.

El texto narra con muchos detalles las razones que llevaban a una joven a huir voluntariamente de su casa con su raptor, que era como sucedía en la mayoría de los casos, a qué hora era más frecuente hacerlo, qué decían los cánones sobre la manera de proceder, correcta e incorrecta, después de una fuga, quiénes eran los que presentaban una demanda por la desaparición de una mujer de su familia o entorno y se convertían entonces en querellantes, cuál era la resolución del juez. Así nos damos cuenta de que presentaron querellas padres, hermanos, tíos, abuelos, patrones, cuidadores y la misma mujer raptada, señalando el delito. Es importante destacar que de 326 casos de padres querellantes, sólo 110 correspondían a los padres varones y 216 eran presentadas por las madres, quienes a su vez eran solteras, viudas, abandonadas; en resumen mujeres que no vivían bajo los lineamientos de lo que debía ser la familia, según el modelo de la Iglesia y la ley.

Entre los oficios de las mujeres querellantes encontramos alfareras, comerciantes, costureras, directoras de primaria, doméstica, hiladora, lavandera, molendera, planchadora, servidora, torcedora, trenzadora, encargada de una fonda y quienes no tenían una ocupación o no la manifestaron. Igualmente podemos conocer los oficios a que se dedicaban los hombres querellantes y el que des- 
empeñaban las propias plagiadas y precisamente al hecho de estar fuera de casa y no en el hogar como correspondía a toda señorita decente, era una de las razones que en la época se esgrimían para haber perdido el honor propio, que era indisoluble del familiar y que lesionaba directamente al de los varones.

Estos datos aparentemente simples de lo que hacían todos estos actores sociales no lo son, pues está el testimonio involuntario, como bien lo señaló el doctor Carlo Ginzburg en el seminario que impartió el 3 de noviembre en la Universidad de Guadalajara. ¿Qué significa que las chicas que se dedican al servicio doméstico o a otras actividades remuneradas y realizadas fuera de casa, pero que son extensión del hogar, declararan que "no hacían nada" cuando se les preguntaba por su ocupación? Si las raptadas o los querellantes sabían firmar o no, eso nos habla de sus niveles de escolaridad. Otras lecturas entre líneas y no tanto, son puestas en evidencia por la autora; por ejemplo, lo que las mujeres debían saber de sexualidad antes de ejercerla, porque ellas eran responsables de su desfloración al insinuarse a un varón, en quien estaría mal visto no demostrar su virilidad al aceptar relaciones carnales. La serie de artilugios a que los muchachos o señores, según la edad, recurrían para convencer a las raptadas de que huyeran con ellos, cuántos realmente estaban dispuestos a cumplir con su palabra, cuántos la cumplieron de facto y qué sucedió cuando no, es parte de lo que encontraremos a la largo de varios capítulos.

También tenemos los relatos de quienes fueron testigos de los robos de chicas, quienes las alentaron a la huida o engañaron para que fueran presa fácil de los raptores. Chicas de 14 años incluso fueron víctimas del delito en cuestión. La fama pública que tuviera la mujer raptada, tenía mucho que ver con lo que se resolvía sobre su caso en el juicio. Veamos el siguiente ejemplo:

Juan Loza, un sastre de veintitrés años de edad, aceptó ante el juez su noviazgo con Celerina, aclarando que se la llevó con su consentimiento y que hizo "uso de ella todos los días" hasta que los detuvieron, pero sin haberle "prometido casarse" en ningún momento; sin embargo, estaba dispuesto a hacerlo, siempre y cuando la madre de ésta, la señora Godínez, lo dejara de "perjudicar". Además esta no era la única vez que hizo uso de su novia, pues en otras veces tuvo con ella "accesos carnales" pero la primera vez que esto sucedió "la encontró desflorada".

En su segunda declaración, Juan dijo que sabía que Celerina era desde hacía mucho tiempo, una mujer de "mala conducta" pues estuvo trabajando en el lupanar que se conoce con el nombre de "El Conejo Blanco" y que para salir de ahí, el señor Eduviges Martínez, dio una responsiva a la jefatura de Policía (p. 190).

Celerina no pudo presentar las cartas en las que su novio le hizo promesas de matrimonio, ella se había salido voluntariamente de su casa, no había más que discutir.

Otro punto importante es que las madres se podían presentar a denunciar la desaparición de sus hijas sólo en caso de que el padre estuviera ausente, pues este era el cabeza de familia, y por tanto le correspondía solicitar la restitución de su honor y ante la ley era el único con categoría 
como demandante. ¿Y si él fuera el raptor? Nos narra como muchas chicas salieron del brazo del novio huyendo de la violencia doméstica de casa.

En este rico texto, Laura demuestra que el delito de rapto era una práctica común entre los estratos sociales medios y bajos de Jalisco y que muchas familias se iniciaron fuera de la legitimidad del Estado, la Iglesia y la sociedad, pero no sólo eso, nos da cuenta de cómo el matrimonio es una construcción de las clases hegemónicas para perpetuar el patrimonio de las familias contrayentes y es parte una cultura patriarcal que va imponiéndose en quienes no tenían que heredar más que una vida poco morigerada a sus descendientes; clases medias y baja estofa que paulatinamente van introyectando patrones que representaban la modernidad: unirse como pareja bajo rituales católicos, así como también con firmas de contratos legales respaldados por el Estado, rituales que una vez realizados constreñían a la pareja en una relación monógama que por "fuerza", a decir de los médicos de entonces, era la recomendada por la higiene, además de por la ley y las buenas costumbres.

Hombres y mujeres haciendo su vida cotidiana nos dan pistas del contexto que los rodeaba, de la superestructura en la que estaban inmersos, pero que no seguían este modelo sin cuestionar, puesto que acudían al rapto, así fuera consensuado, como antesala del matrimonio, a veces "respetando" a la raptada dejándola en depósito en una casa honorable, otras iniciando su vida sexual de manera inmediata. Lo sorprendente para la autora es que muchas parejas decidieran empezar así lo que luego sería una unión en toda regla, o como dirían algunas personas "como Dios manda".

La trascendencia del texto es que se explica un proceso social local para llegar a entender uno más amplio y variado: la visión del sexo, de la pareja, del amor, no sólo de las clases comúnmente ignoradas o silenciadas, sino de las que si podían externar su pensar elaborando artículos, médicos y periodísticos, leyes, opúsculos sobre el deber ser de la época.

Sin más comentarios que puedan distraerlos de buscar por ustedes mismos lo interesante del libro, los invito a dar un paseo por la historia de quienes parecían no tenerla. 